\title{
O paradigma médico-legal Médico-legal paradigm
}

\author{
Daniel Romero MUÑOZ1, Daniele MUÑOZ², Marcos de ALMEIDA ${ }^{3}$
}

\begin{abstract}
MUÑOZ, D. R.; MUÑOZ, D.; ALMEIDA, M. O paradigma médico-legal. Saúde, Ética \& Justiça, 5/7(1-2):1-5, 2000-2002.
Resumo: Uma lesão incisa é sempre causada por instrumento cortante? Um punhal, do ponto de vista médico-legal, que tipo de instrumento é? Tomando como exemplo um caso pericial, os autores discutem o diagnóstico médico-legal do instrumento causador de lesão, questão que pode provocar controvérsias jurídicas se não for adequadamente conduzida. Concluem que um paradigma médico-legal deve nortear toda discussão a respeito desse diagnóstico.
\end{abstract}

Unitermos: Medicina legal/legislação \& jurisprudência. Perícia médica. Prova pericial. Ética médica.

\section{Introdução}

o consultarmos alguns livros de Medicina
Legal, encontramos a afirmação que o punhal é um a exemplo de instrumento pérfurocortante. Imagine então o seguinte caso médicolegal: um legista é chamado para depor sobre uma necropsia que realizou; o advogado de defesa, ao interrogá-lo, apresenta-Ihe a seguinte questão:

- Doutor, eu estive lendo estes livros de Medicina Legal (e apresenta ao legista uma pilha de livros) e todos eles afirmam que o punhal é um exemplo de instrumento pérfuro-cortante, o Senhor concorda?

O legista acede e o advogado de defesa lhe dirige a segunda pergunta:

- Doutor, o Senhor poderia dizer aos Senhores Jurados o que significa instrumento pérfuro-cortante?

- De modo simples, é um instrumento que perfura e corta, responde o médico.

O causídico frisa aos jurados:

- Notem, Senhores Jurados, que o punhal, como esclareceu o Doutor Médico-legista, é um instrumento que perfura e corta, certo Doutor?

\footnotetext{
1. Professor livre-docente da Disciplina de Medicina Legal da Faculdade de Medicina da Universidade de São Paulo e de Medicina Legal e Bioética da Faculdade de Medicina da Santa Casa de São Paulo, Laboratório de Investigação Médica - LIM-HCFMUSP.

2. Acadêmica do Curso de Medicina da Universidade de Mogi das Cruzes, SP.

3. Professor Titular da Disciplina de Medicina Legal e Bioética da UNIFESP.

Endereço para correspondência: Daniel Romero Muñoz. Rua Teodoro Sampaio, 115. CEP 05405-000. São Paulo, SP. Brasil. E-mail: danielmunoz@bol.com.br
} 
À concordância do legista, o defensor exibe-lhe então um laudo necroscópico, acompanhado da seguinte indagação:

- Doutor, este laudo é seu, isto é, o Senhor foi o signatário deste laudo?

O perito examina o documento e, à positividade de sua resposta, o advogado esclarece ao Júri que aquele é o relatório da necrópsia da vítima, cuja morte motivou a presente ação penal. Ele pede então ao legista:

- Doutor, o Senhor pode dizer aos Jurados qual foi a causa da morte?

- Foi TCE, que significa traumatismo crânioencefálico, explica o legista. E o jurista emenda:

- E qual foi o instrumento que produziu esse TCE?

- Instrumento contundente, afirma o facultativo. Ao que o advogado pergunta:

- E por que o Senhor concluiu que foi instrumento contundente? Que elementos o Senhor encontrou na necropsia que o levaram a concluir que a morte foi produzida por instrumento contundente?

- Havia um hematoma entre o couro cabeludo e o crânio, uma fratura de crânio nesse local e um grande hematoma entre a dura-máter e o crânio, indicando ação contundente do instrumento, esclarece o médico. O defensor insiste:

- Então, Doutor, com esses elementos pode-se afirmar, categoricamente, que o instrumento que provocou a morte "não foi pérfuro-cortante", certo? O legista anui e o advogado se dirige ao Juri:

- Lembro aos Senhores Jurados que o principal elemento de prova levantado contra o réu, é que ele foi visto saindo da casa da vítima portando um punhal, que é a peça número tal. Ele aponta para um grande punhal (cerca de 40 centímetros de comprimento), com um enorme cabo de aço maciço, que deve pesar mais de 1 quilo e continua:

- Senhores jurados, deve-se salientar duas afirmações do nosso digno perito médico: a primeira é que o punhal é um instrumento pérfuro-cortante; a segunda é que a morte da vítima foi produzida por instrumento contundente e que não poderia ter sido causada por instrumento pérfuro-cortante. Portanto, Senhores, a conclusão é óbvia: o punhal portado pelo réu não foi o instrumento que produziu a morte da vítima.

\section{Contradições médico-legais}

O promotor público inicia sua inquirição ao legista pelo ponto crucial do caso:

- Doutor, este punhal poderia ter produzido o TCE que causou a morte da vítima?

À resposta positiva do médico, ele o questiona:

- Um golpe violento, desferido com o cabo do punhal, poderia provocar a lesão que matou a vítima?

O perito concorda com o representante do Ministério Público e este conclui com a questão:

- Então, o punhal pode ter sido o instrumento contundente que o Senhor relata em seu laudo?

À afirmação do médico, o promotor encerra suas perguntas e o magistrado, na tentativa de elucidar o ponto controverso, indaga ao perito:

- Doutor, o punhal é um instrumento pérfurocortante ou contundente? Afinal o Senhor há de convir que ele não pode ser as duas coisas simultânea-mente?

Do modo como foi colocada a questão durante o julgamento, parece óbvio que o promotor público tem razão. Mas a crítica do juiz é pertinente: o instrumento atuou como pérfuro-cortante ou como contundente, ou atuou dos dois modos ao mesmo tempo? O que permitiu ao advogado de defesa concluir, com tanta lógica, que o punhal não poderia ter sido a arma do crime? O legista falhou ao responder às perguntas que the foram formuladas, ou o livros de Medicina Legal é que estão errados, isto é, o punhal não é, realmente, um exemplo de instrumento pérfuro-cortante?

Essa contradição se estende, às vezes, à própria sala de aula, quando o aluno pergunta:

- Professor, uma faca "laser" (aquela com o fio todo serrilhado), que tipo de instrumento é?

Não é raro que o professor enverede por uma 
explicação sobre tipo de instrumento ou agente e seu modo de ação, separando os dois (tipo e modo de atuação), confundindo o aluno com contradições, como a que foi colocada pelo juiz.

O problema central, aqui, é:

- Como é feito o diagnóstico do instrumento em Medicina Legal, isto é, como o médico-legista determina o tipo de instrumento que produziu a lesão? De que elementos ele se vale para esse diagnóstico?

\section{A classificação médico-legal dos agentes vulnerantes exógenos}

Alguns livros de Medicina Legal abordam o estudo dos traumas a partir da classificação médicolegal da causalidade do dano, que se constitue na sistematização das energias, agentes ou instrumentos vulnerantes exógenos ${ }^{1,2}$.

A classificação de Borri ordena os tipos de energias, agentes ou instrumentos lesivos em mecânicos, físicos, químicos, físico-químicos, bioquímicos, biodinâmicos e mistos ${ }^{1}$. Os mecânicos são subdivididos em perfurantes, cortantes, contundentes, pérfuro-cortantes, corto-contundentes e pérfuro-contundentes. Alguns autores modificaram essa classificação, adaptando-a melhor às exigências da perícia médico-legal ${ }^{3}$, uma vez que o principal objetivo da sistematização do conhecimento é facilitar o seu emprego, servir à práxis; se ela atrapalhar, deve ser modificada ou abolida.

Ocorre que a prática médico-legal, o dia a dia das perícias médicas, é o exame do periciando. É o visum et repertum ${ }^{1,2}$. Ou seja, é a partir desse exame que o especialista em Medicina Legal faz seus diagnósticos e conclusões para esclarecer à Justiça. Portanto, uma classificação médico-legal dos agentes ou instrumentos lesivos só pode estar baseada em elementos que possam ser extraídos do exame do periciando. No caso da traumatologia forense a base da classificação dos agentes vulnerantes exógenos é o tipo de lesão, fato que não é frisado pela maioria dos autores.

\section{O artifício didático: ensinando na contramão}

Por outro lado, existem compêndios que definem alguns instrumentos pelas suas características morfológicas ${ }^{4}$, outros afirmam que certos utensílios são tipos específicos de agentes vulnerantes, tais como tesoura é pérfuro-cortante ${ }^{5}$, martelo é contundente $^{6}$, navalha é cortante ${ }^{7}$ etc. É freqüente também os textos médico-legais partirem dos agentes ou instrumentos para explicarem como é a lesão que eles produzem ${ }^{3,8,9}$. Existem ainda autores que iniciam sua exposição pela lesão, mas ao se referirem a um tipo particular ferimento apontam, em seguida, um objeto como sendo o típico instrumento que a produz (por exemplo, lesão contusa-pedra) ${ }^{10}$. Este tratamento do tema pode ser um artifício didático para facilitar a exposição do assunto, entretanto pode causar muitas contradições, como as do caso acima relatado. $O$ fato é que este enfoque vem na contramão da práxis pericial médica; é uma abordagem de trás para a frente, uma vez que, na prática, o médico parte da lesão para diagnosticar o instrumento, isto é, o objeto de estudo do médico é o ser humano, e neste capítulo da Medicina Legal (traumatologia forense) é o ser humano traumatizado, com lesão. De modo simplório, podemos dizer que, no caso do médicolegista, o objeto de estudo é o ser humano lesado; o que ele examina é a lesão (e a pessoa lesada) e é através do exame pormenorizado das características da lesão que ele faz o diagnóstico do instrumento que a produziu.

Portanto, se o especialista em Medicina Legal tem uma lesão para examinar, ou uma boa descrição da mesma, ele pode dizer qual foi o tipo de instrumento que a produziu, de acordo com a classificação médico-legal dos agentes vulnerantes 
exógenos. Em outros termos, tendo uma lesão definida (por exemplo, uma solução de continuidade no hemitórax direito, de forma navicular, com $7 \mathrm{~cm}$ de comprimento e $1,5 \mathrm{~cm}$ em sua porção mais profunda, bordas lisas e regulares demonstrando secção uniforme das fibras do tecido, com duas caudas, sendo uma na parte mais profunda do ferimento e a outra bem superficial, contendo inclusive em sua extremidade secção apenas da epiderme), suas características são fatos que, documentados pelo perito, permitem estabelecer o tipo de lesão (no exemplo dado, lesão incisa). Com base nesse diagnóstico da lesão ele determina o tipo de instrumento que a produziu (instrumento cortante, no exemplo supracitado).

Se, entretanto, o ponto de partida for 0 instrumento, com a intenção de se saber que tipo de lesões ele pode produzir, então tudo se complica porque as características da lesão se modificam segundo vários fatores: características morfológicas do instrumento, seu modo de ação, intensidade da força aplicada, local da lesão, etc. Pode-se especular para saber os tipos de lesões possíveis de serem produzidas por um determinado instrumento. Neste caso, porém, estaremos partindo de hipóteses na tentativa de obter respostas, isto é, se tenho um instrumento com as características $x, y, z$, se ele atuar de um modo específico, com uma intensidade de força definida, sobre uma região corpórea determinada, provavelmente produzirá uma lesão de tal tipo, com base nos elementos analisados em experiências prévias. Nas ciências médicas, porém, o método empregado para se estabelecer o diagnóstico segue o sentido inverso: parte-se dos fatos (dados observados no exame do paciente) para a hipótese diagnóstica. O perigo de se inverter esse sentido é que, em vez de ciência, poderemos estar trabalhando com ficção científica.

\section{Conclusão}

Nas perícias médico-legais, portanto, o diagnóstico do instrumento causador da lesão deve seguir o paradigma: é a lesão que denomina o instrumento, nunca o inverso.

Em outros termos: dê uma lesão a um médicolegista e ele poderá te dizer o tipo de instrumento que a produziu, porque é pelo estudo detalhado das características da lesão que ele diagnostica o instrumento causador. $O$ diagnóstico do instrumento só tem sentido a partir da existência de uma lesão. Este é um dos principais motivos que tornam a descrição pormenorizada das lesões uma obrigação do legista ao fazer o seu laudo. Partir do instrumento para se chegar à lesão é um exercício de pura especulação.

O paradigma supracitado nos conduz a uma afirmação categórica como resposta à pergunta inicial deste trabalho:

"A lesão incisa é sempre causada por instrumento cortante", porque, se após examinar a lesão, o médico diagnosticou-a corretamente como incisa, por definição, o instrumento que a causou será, obrigatoriamente, do tipo cortante.

E qual foi o erro do médico legista quanto ao punhal? Seu erro foi concordar, integralmente, que o punhal é um exemplo de instrumento pérfuro-cortante. O punhal só é instrumento pérfuro-cortante quando produz uma lesão pérfuro-incisa. É claro que, se ele atuar de modo típico, provavelmente, causará uma lesão desse tipo.

MUÑOZ, D. R.; MUÑOZ, D.; ALMEIDA, M. de. Medico-legal paradigm. Saúde, Ética \& Justiça, 5/7(1-2):1-5, 2000-2002.

Abstracts: Is an incision wound always caused by a cutting instrument? From a forensic point of view, what sort of instrument is a knife? Using as an example a routine case the authors discuss the medico-legal diagnosis on the instrument that caused an injury. That question can easily be rather misleading, if not properly judged. They conclude that a medicolegal paradigm should be used to frame any type of discussion on the correct diagnosis.

Keywords: Forensic medicine/legislation \& jurisprudence. Medical inspection. Expert testimony. Ethics, medical. 
MUÑOZ, D. R. et al. O paradigma médico-legal.

\section{Referências}

1. Fávero, F. Medicina legal. São Paulo: Martins, 1973.

2. França, G.V. Medicina legal. Rio de Janeiro:

6. Bonnet, E.F.P. Medicina legal. Buenos Aires: Lopez, 1980. Guanabara Koogan, 2001.

7. Achával, A. Manual de medicina legal. Buenos Aires: Abeledo-Perrot, 1994.

3. Spitz, W.U. Medicolegal investigation of death. Springfield: Charles Thomas, 1993.

4. Almeida Junior, A.F.; Costa Junior, J.B.O.E. Lições de medicina legal. São Paulo: Nacional, 1977.

5. Calabuig, J.A.G. Medicina legal y toxicologia. Barcelona: Masson, 1998.

8. Simonin, C. Medicina legal judicial. Barcelona: Jims, 1973.

9. Cuaron, A.Q. Medicina forense. México: Porrúa, 1996.

10. Maranhão, O.R. Curso básico de medicina legal. São Paulo: Revista dos Tribunais, 1984. 